\title{
NEIGHBORHOOD RESEARCH FROM A SPATIALLY ORIENTED STRENGTHS PERSPECTIVE
}

\section{Carol T. Mowbray}

University of Michigan School of Social Work and

Department of Psychology

Michael E. Woolley

University of Michigan Schools of Social Work and Education

Andrew Grogan-Kaylor, Larry M. Gant, Megan E. Gilster, and Trina R. Williams Shanks

University of Michigan School of Social Work

\begin{abstract}
Research investigating neighborhood effects on children and families has been largely deficit and individual-focused, investigated structural variables, and has typically produced equivocal findings and small effect sizes. We suggest an approach focused on community strengths and resources that stresses the role of measures of social interaction variables and the utilization of analytic strategies that model the spatial and nested nature of contextual effects. To that end, we offer a community resilience model that includes both community-level risk and protective factors, and suggests sources to obtain community-level strengths data. We also provide
\end{abstract}

\footnotetext{
This article is dedicated to the memory of Carol T. Mowbray. Four months after being diagnosed with advanced gall bladder cancer, Carol died on August 23, 2005, at the much too young age of 57. Carol was the organizing force in bringing the authors on this article together to explore the potential applications of spatial and multilevel methods to studying complex community-level social processes. Her unwavering strengths perspective, which she not just believed but lived, toward research, practice, colleagues, and students, is reflected in the theoretical orientation of this article. The "GIS Group" she started has carried on after her death and is currently engaged in empirical analyses inspired by this first conceptual article. In so many ways, this article is an example of the kind of contributions Carol made to the fields of psychology and social work during the course of her career. Carol was most impressive at bringing many people to the table and finding the strengths and potential contributions of each. Carol has been a deeply valued mentor to many developing researchers over the years. She is profoundly missed by the assistant professors and doctoral students here at the University of Michigan, who were currently being mentored by her, some of whom are authors of this article. This research was supported, in part, through a grant from the National Institute of Mental Health, \#R24 MH 051363 to the University of Michigan School of Social Work, Center for Research on Poverty, Risk and Mental Health

Correspondence to: Michael E. Woolley, University of Michigan, 3849 School of Social Work Building, 1080 South University Avenue, Ann Arbor, MI 48109-1106. E-mail: mwoolley@umich.edu
} 
a guide for locating community resource data appropriate for use in neighborhood effects research utilizing geographical information systems, multilevel modeling, and spatial analytic strategies. Finally, we discuss the challenges and issues to be addressed in further developing a strategy for investigating neighborhood effects from a strengths perspective. (C) 2007 Wiley Periodicals, Inc.

The impact of environmental factors on all aspects of child development has become increasingly clear over the past three decades. Pioneering works by Bronfenbrenner (1979), Garbarino and Sherman (1980), Garmezy, Masten, and Tellegen (1984), Rutter (1987), Werner and Smith (1982), and others have highlighted the impact of the physical, social, and economic environment on childhood development. The concept of child resilience and the quest to identify the factors that promote healthy development emerged from these seminal works. More recently, researchers have begun the study of the effect of neighborhoods on development. Unfortunately, much of this research has had a deficit bias and a focus on individual outcomes (Wandersman \& Nation, 1998).

We suggest that this situation can be improved by a theoretical model of community resilience that incorporates both spatial and multilevel perspectives and the application of analytic strategies appropriate to test aspects of such a model. After an overview of current research on neighborhood effects, we offer a theoretical model to guide neighborhood research. We then describe tools for research informed by our proposed model including geographical information systems, multilevel modeling, and spatial statistical analysis. Finally, we present local and national data sources amenable to this research agenda.

\section{RESEARCH ON NEIGHBORHOOD EFFECTS}

In a recent review, Sampson and colleagues (2002) reported the literature supports the utility of four valid neighborhood constructs: (a) social ties and interactionsresources that are derived from interpersonal processes often termed social capital; (b) norms and collective efficacy-the extent to which neighbors are willing to intervene on behalf of the public good; (c) institutional resources-the quality, quantity, and diversity of organizations that provide services to members of the community; and (d) routine activities-land use, daily activity patterns, and access to the resources and organizations described above.

Sampson and colleagues (2002) also reported increased application of spatial analysis approaches to examine community-level structural characteristics and interpersonal processes; for example, examining proximity and access to resources, or conversely resources located outside of geographical neighborhood boundaries that influence neighborhood residents. Other spatial factors include the disconnect between census defined neighborhoods and real world patterns of interactions and activities. Spatial analysis approaches can account for these factors by creating a model that more closely parallels the dynamics of "neighborhood" on the ground. The authors conclude that a lot is known about structural aspects of neighborhoods; however, much work needs to be done on the interplay between structural characteristics and social processes. 
Leventhal and Brooks-Gunn (2000) recently provided an overview of neighborhood research focused on youth. They reported research studies have primarily investigated three outcomes: (a) school readiness and achievement, (b) behavioral and emotional problems, and (c) sexuality and childbearing. Similar to the Sampson review, they found research primarily investigated three factors: (a) institutional resources, (b) relationships, and (c) norms and collective efficacy. These authors asserted that there is ample accumulated evidence for the impact of structural variables, including economics and residential instability, on developmental outcomes. Further, the authors suggested that multilevel analytic approaches are required to calculate reliable estimates of such neighborhood effects. Leventhal and Brooks-Gunn also observed that census data provide measures of structural variables; however, surveys, observational data, and administrative data must be utilized to study social variables.

Neighborhood research has primarily focused on risk factors, most of which disproportionately affect poor families. Evans (2004) recently reviewed this literature and described the increased severity and number of risk factors experienced by children whose families live in poverty, as follows: (a) crowded and noisier environments, (b) greater air and water pollution and exposure to lead-based paint, (c) lower quality daycare, (d) less family-school interaction, (e) fewer family organizational involvements, (f) more physically deteriorated and dangerous neighborhoods, (g) higher levels of crime and violence, (h) more family conflict, (i) higher residential instability, (j) less social support/social capital, (k) more authoritative parenting, (l) watching more TV and being read to less, (m) less access to healthy food, and (n) less access to books or computers. It has also been pointed out that these factors tend to cluster for poor families compounding their effect by the resulting accumulated risk exposure (Evans \& English, 2002). Evans (2004) concluded that researchers must change the way variables for income and socioeconomic status are treated in analytic models to more effectively recognize the ecological impact of poverty as a central issue in developmental outcomes, as opposed to treating them as unexplained, confounding, or nuisance variables to be controlled for (Rabe-Hesketh \& Skrondal, 2005).

\section{SUMMARY AND CRITIQUE OF NEIGHBORHOOD RESEARCH}

The late 1980s and 1990s has seen an explosion of studies that consider the impact of neighborhood effects on youth (Brooks-Gunn, Duncan, \& Aber, 1997; Dietz, 2002; Leventhal \& Brooks-Gunn, 2000; Sampson et al., 2002) partly because researchers such as Wilson $(1987,1996)$ proposed widely read hypotheses on the impact of industrial changes and the restructuring of urban neighborhoods. Analyses of census and other data have emphasized the negative influence of hypersegregation and the increased concentrations of poverty (Jargowsky, 1997; Kasarda, 1993; Massey, 1996). Although neighborhoods are frequently found to be statistically influential, effect sizes of findings have been modest (typically $5 \%$ of the variance or less).

These effect sizes may be due to incomplete models and methods. Many studies relied on sociodemographic and economic data from the census, such as poverty levels and racial heterogeneity. Researchers have noted (Brooks-Gunn et al., 1997; Leventhal \& Brooks-Gunn, 2000; Sampson et al., 2002) data from the census, although well measured, easily followed over time, and replicable with access to geographic files are lacking. First, census clusters are imperfect proxies for how residents define neighborhoods. Second, census data do not capture the physical features of neighborhoods, 
which requires observational or survey data. Third, census clusters do not consider spatial dependence or the influence of surrounding areas. Fourth, considering only current neighborhood characteristics does not capture important dynamics of change over time. Fifth, census data do not capture social or organizational aspects of neighborhoods, both important theoretical concepts, such as social capital and collective efficacy. Finally, census data are available only every ten years, limiting the ability to model change.

\section{A SPATIAL AND MULTILEVEL COMMUNITY RESILIENGE MODEL}

While community effects researchers have built a substantial body of literature documenting the impact of risk factors on community-level outcomes, not all individuals and communities exposed to risks exhibit the associated negative outcomes. Clearly, other factors are at work which have a positive impact on outcomes and which could be the focus of a strengths-based, community-level approach to prevention and intervention programming. Resilience researchers have documented many individual-level protective factors that impact child developmental outcomes, as follows: temperament, intelligence, self-reliance, future expectations, humor, problem-solving skills, family warmth and cohesion, parental supervision, family economics, family-school communication, supportive teachers, religious and spiritual beliefs, peer groups, and participation in extra-curricular activities (Fraser, Kirby, \& Smokowski, 2004; Garmezy, 1993; Moos, 2002; O’Donnell, Schwab-Stone, \& Muyeed, 2002; Richman, Bowen, \& Woolley, 2004; Seccombe, 2002).

Research has only begun to examine the factors that lead to resilient communities. Community resilience is proposed to emerge from community-level resources that are embedded within or accessible to communities, which can provide a community with the ability to adapt in positive ways to risk. Additionally, we suggest that resilient communities have the capacity to identify and access resources to replenish utilized resources to prepare for future risk events. Specifically, we suggest that three types of resources contribute to resiliency: social capital resources, institutional resources, and economic resources.

Social capital resources include the promotive and protective influences that grow out of the social relationships between and among residents in communities. These relationships give rise to shared values and mutual trust that together determine the quantity and quality of cooperative action. Examples include the frequency and nature of social interactions between neighbors, the social ties between community members such as churches, and neighborhood centers, and the resultant collective efficacy to intervene on behalf of the community good.

Institutional resources encompass the number, nature, mission of, and access to local organizations and agencies that serve community members; such organizations include schools, community mental health centers, recreational programs, libraries, childcare facilities, medical services, social service agencies, and employers.

Economic resources include economic community strengths such as employment opportunities and unemployment rates, family income and assets, land use and property values, housing availability and cost, and private and public investments in local infrastructure.

Figure 1 presents our proposed community resilience model that includes these resilience resources as well as three community-level risk factors that have deleterious 


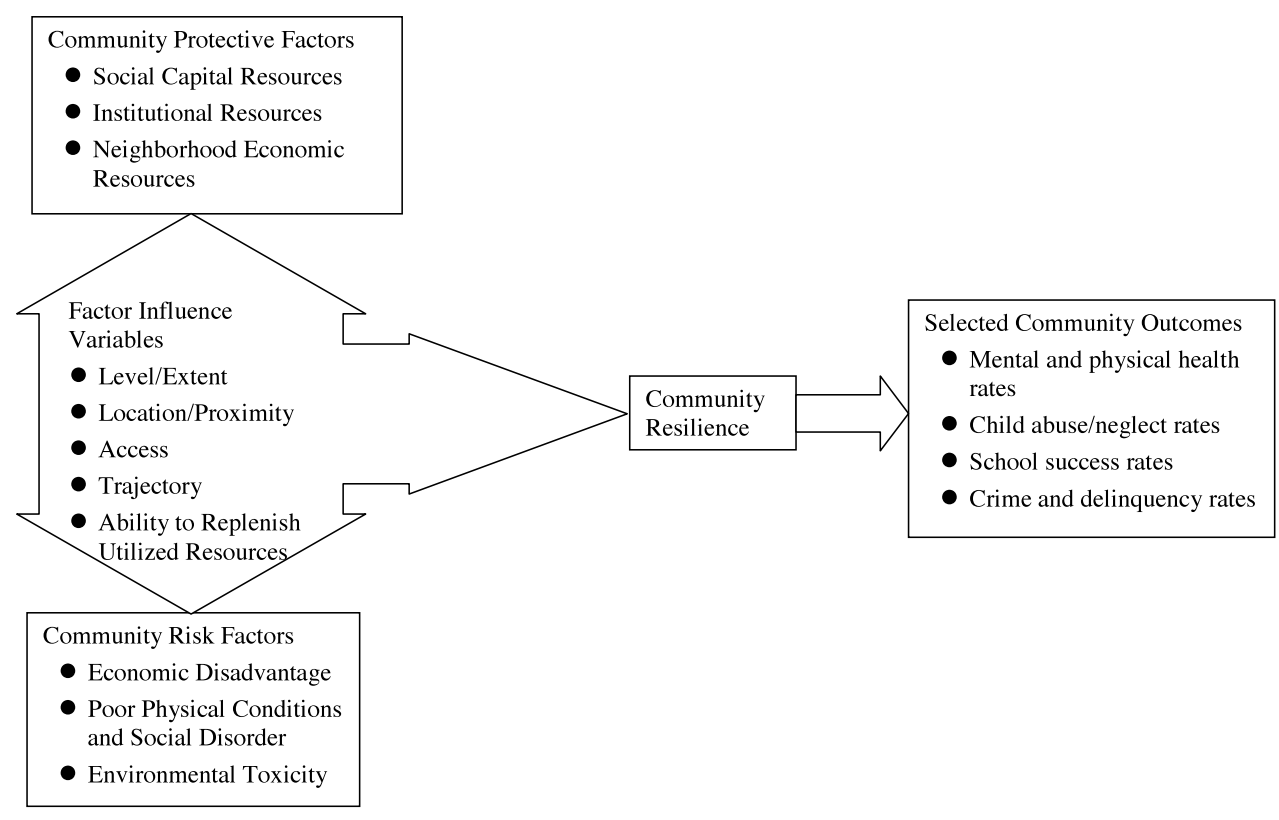

Figure 1. Community resilience model. Note. Informed by: Evans (2004); Leventhal and Brooks-Gunn (2000); Moos (2002); Sampson et al. (2002); and Wandersman and Nation (1998).

impact on outcomes of community members. Economic disadvantage includes indicators such as poverty, unemployment, and property values. Poor physical conditions and social disorder include transience, crime, vandalism, abandoned buildings, and poor infrastructure maintenance (such as streets, parks, and housing). Finally, environmental toxicity includes air pollution, noise, lead-based paint, water quality, and other such factors (Evans, 2004; Sampson et al., 2002).

From a spatial perspective, the impact of these six factors is a function of (a) the level or extent of the factor in the community, (b) the location and proximity of the factor to the community and residents, (c) the level and ease of access, and (d) the trajectory of the factor. The community outcomes depicted in the model include (a) health outcomes, mental and physical, (b) child abuse and neglect rates, (c) school success rates, and (d) crime and delinquency rates. Testing the model requires obtaining data on protective factors as well as tools to appropriately utilize and analyze nested spatial data. Those tools include the ability to spatially locate a risk or protective factor as well as multilevel and spatial statistical models to appropriately analyze such data. In the next section, we will briefly describe accessible strengths-oriented databases, which could be used to test our proposed model.

\section{Spatial Data Sources}

National spatially located data on community resources. One reason for the prevalence of risk indicators in research is that risk data are commonly available, such as census and crime data. Locating secondary data on community resources that can be spatially located is challenging. Table 1 provides a list of such sources, the level at which they can be spatially located, the indicators that are available, and notes on the data 


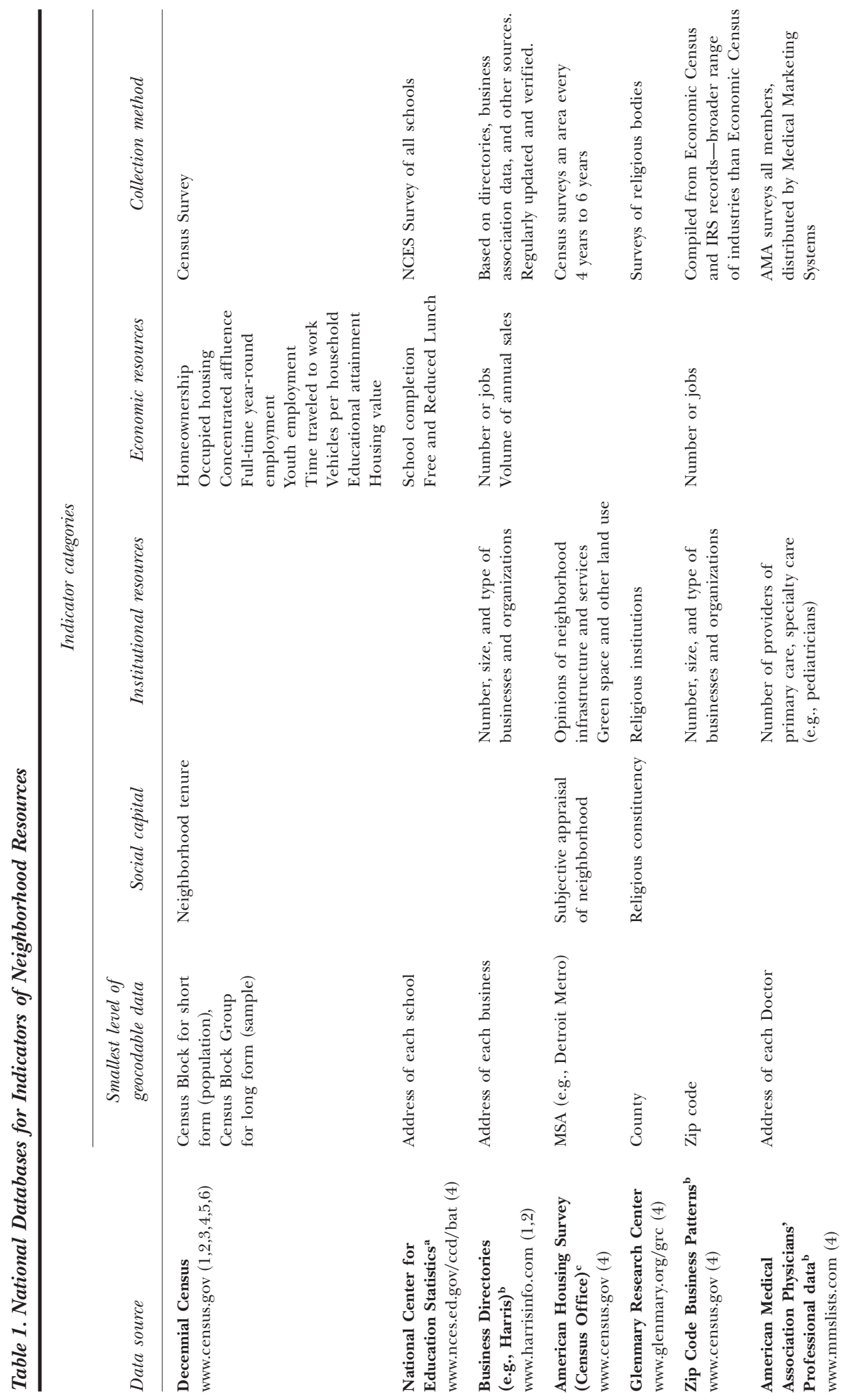




\section{Neighborhood Spatial Strengths Perspective 673}
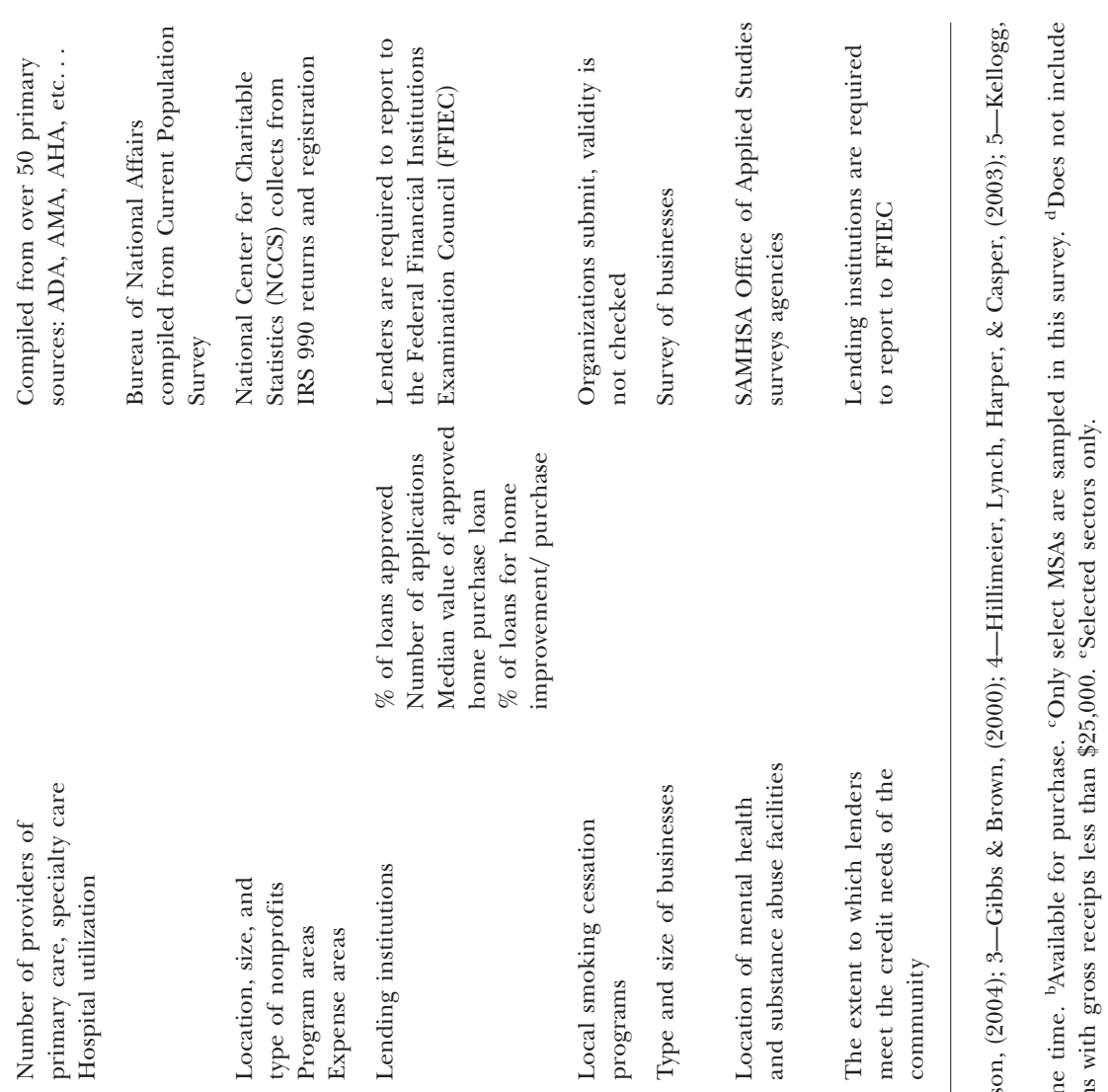

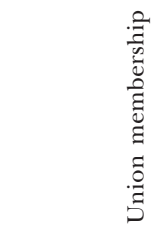
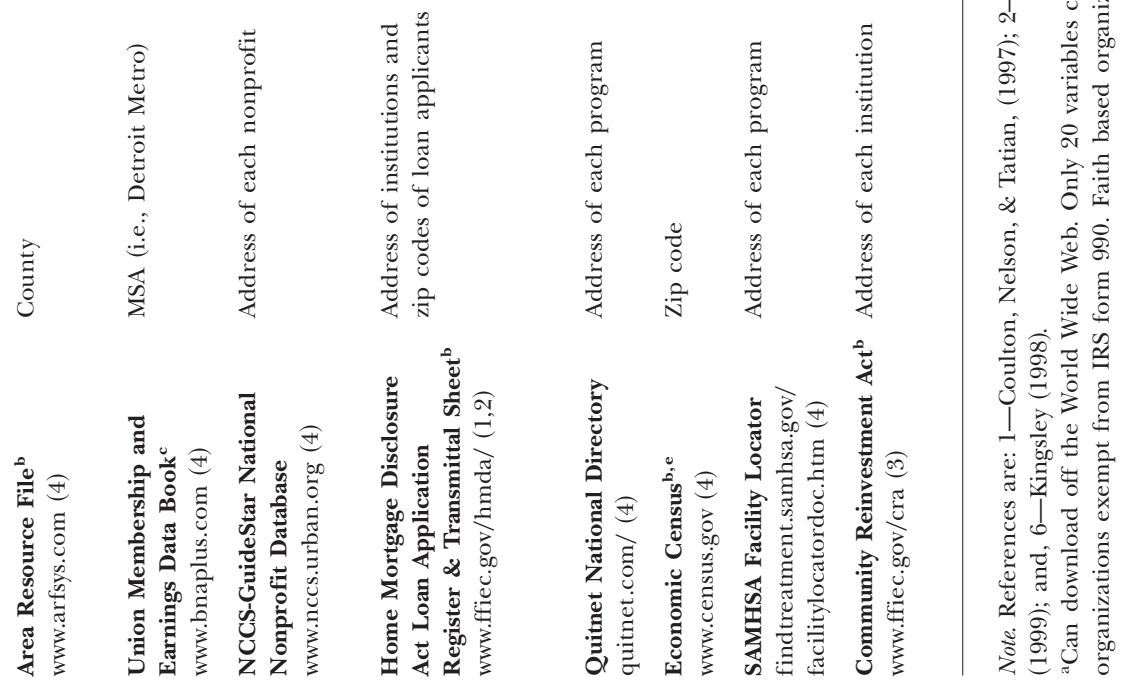
collection methods used. Using the community resilience model, the indicators listed are categorized as to the community protective factors they represent-social capital, institutional resources, and neighborhood economic resources. The first 15 data sources presented in the table are national databases. Census data are free of charge, however, many other national databases must be purchased. Costs vary and often depend on the number of cases and variables requested. Much data are mandated by law and collected at state, county, or local levels; therefore, are available nationally but requiring separate local contacts for acquisition. The effort is worthwhile, as data in regional databases are more likely to be geocodable at the address level.

Local spatially located data on community resources. Table 2 details available local data sources. In recent years, several communities have implemented neighborhood-level information systems to inform local policy decisions. Through the National Neighborhood Indicators Partnership (NNIP), the Urban Institute collaborated with communities interested in developing neighborhood-level information systems and in facilitating the use of the data by community leaders and residents (www.urban.org/nnip). Through this initiative, communities collected indicators of neighborhood-level protective factors by surveying community organizations and residents. Researchers should examine these surveys to inform their own strategies for neighborhood data collections. Surveys of community organizations can provide indicators of participation in, and of the quality, quantity, and diversity of, institutional resources.

\section{Utilizing Data to Test the Model}

Spatially locating the data. Developed in the 1970s, geographic information systems (GIS) refers broadly to a system of computer software and procedures designed to capture, manage, manipulate, analyze, model, and display spatially referenced data for solving complex problems (Korte, 2001). GIS applications are increasingly used in mapping and examining relationships between public health and local conditions. For example, the relationship between area income and disease (Chen, Breiman, Farley, Plikaytis, Deaver, \& Cetron, 1998) and the spatial clustering of health conditions (Getis \& Ord, 1992; Rushton \& Lolonis, 1996). In social services, GIS has been used to identify geographically underserved target populations in order to make decisions about site locations (e.g., Chen, Harris, Folkoff, Drudge, \& Jackson, 1999; Queralt \& Witte, 1998a; Wong \& Hillier, 2001). Interactive GIS maps have also been used to identify services that meet client needs (Robertson \& Wier, 1998; Wier \& Robertson, 1998). GIS has also been applied to social policy advocacy by mapping and visually comparing gang activity in relation to poverty, change in racial/ethnic composition, and resource scarcity (Hoefer, Hoefer, \& Tobias, 1994).

Most GIS articles describe the use of maps as illustrative tools. Only a few inferential statistical analyses have been conducted examining the relationships among mapped variables. Queralt and Witte (1998b) found that income predicts low childcare capacity, especially for licensed center-based facilities. Ernst (2000) examined census tract characteristics as they relate to child maltreatment rates, finding that neglect is associated with economic resources, and physical and sexual abuse with both economic and social resources. Finally, Coulton, Korbin, and Su (1999) examined child maltreatment, but found that variation was greater within neighborhoods than between neighborhoods when controlling for individual risk. Still, these few 


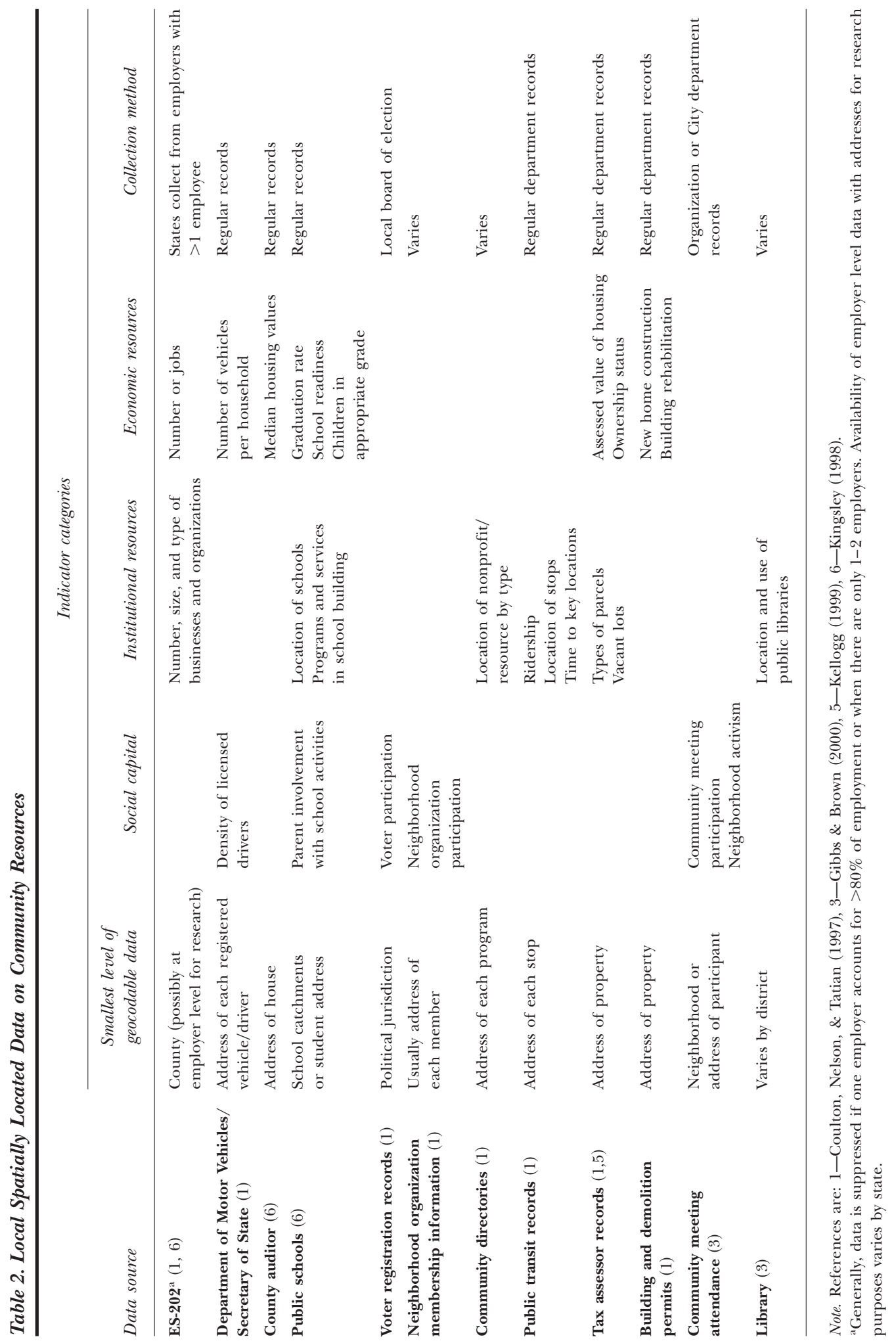


Table 3. Comparison of GIS Tools and Software

\begin{tabular}{|c|c|c|c|c|}
\hline $\begin{array}{l}\text { Tool/Software } \\
\text { Characteristic }\end{array}$ & $\begin{array}{c}\text { GRASS (Geographic } \\
\text { Resources Analysis } \\
\text { Support System) }\end{array}$ & MapInfo & $\begin{array}{l}\text { ArcView } \\
\text { ArcGIS }\end{array}$ & $\begin{array}{l}\text { Internet Maps } \\
\text { (e.g., American } \\
\text { Fact Finder) }\end{array}$ \\
\hline Ease of Use & $\begin{array}{l}\text { Generally for GIS } \\
\text { Professionals }\end{array}$ & $\begin{array}{l}\text { Challenge depends } \\
\text { on level of use }\end{array}$ & $\begin{array}{l}\text { Challenge depends } \\
\text { on level of use }\end{array}$ & Easiest \\
\hline $\begin{array}{l}\text { Time required to } \\
\text { become proficient }\end{array}$ & Weeks to months & Weeks to months & Weeks to years & Almost instantly \\
\hline Operating system & Windows or Unix & Windows or Unix & Windows or Unix & Internet browser \\
\hline Requires programming & Some applications & $\begin{array}{l}\text { Advanced } \\
\text { applications only }\end{array}$ & $\begin{array}{l}\text { Advanced } \\
\text { applications only }\end{array}$ & $\begin{array}{l}\text { For the developer, } \\
\text { not the user }\end{array}$ \\
\hline $\begin{array}{l}\text { Can import databases } \\
\text { (Sybase, Oracle, etc.) }\end{array}$ & $\mathrm{L}$ & $\mathrm{L}$ & $\mathrm{E}$ & $\mathrm{n} / \mathrm{a}$ \\
\hline \multicolumn{5}{|l|}{ Features } \\
\hline $\begin{array}{l}\text { Display maps \& images } \\
\text { (i.e. orthophotos) }\end{array}$ & G & $\mathrm{E}$ & $\mathrm{E}$ & G \\
\hline Classify data & G & G & $\mathrm{E}$ & $\mathrm{L}$ \\
\hline Work with tabular data & G & $\mathrm{E}$ & $\mathrm{E}$ & $\mathrm{n} / \mathrm{a}$ \\
\hline Edit data & G & G & $\mathrm{E}$ & $\mathrm{n} / \mathrm{a}$ \\
\hline $\begin{array}{l}\text { Import data from } \\
\text { other sources }\end{array}$ & $\mathrm{L}$ & G & $\mathrm{E}$ & $\mathrm{n} / \mathrm{a}$ \\
\hline $\begin{array}{l}\text { Converting data to } \\
\text { another format }\end{array}$ & G & G & $\mathrm{E}$ & $\mathrm{n} / \mathrm{a}$ \\
\hline Manages large data sets & G & G & $\mathrm{E}$ & $\mathrm{L}$ \\
\hline $\begin{array}{l}\text { Creates GIS data } \\
\text { from tables }\end{array}$ & G & $\mathrm{L}$ & G & $\mathrm{n} / \mathrm{a}$ \\
\hline $\begin{array}{l}\text { Produces publication } \\
\text { quality maps }\end{array}$ & $\mathrm{n} / \mathrm{a}$ & $\mathrm{n} / \mathrm{a}$ & E & $\mathrm{n} / \mathrm{a}$ \\
\hline $\begin{array}{l}\text { Spatial analysis } \\
\text { (not statistics) }\end{array}$ & G & G & $\mathrm{E}$ & $\mathrm{n} / \mathrm{a}$ \\
\hline Price per user & Free & $\begin{array}{l}\text { Purchase at } \\
\text { www.mapinfolcom }\end{array}$ & $\begin{array}{l}\text { Purchase at } \\
\text { www.esri.com }\end{array}$ & Free \\
\hline
\end{tabular}

Note. Abridged, updated, and adapted from the Washington State Department of Ecology's "Comparison of GIS Tools" (http://www.ecy.wa.gov/services/gis/training/compare.htm). L-Has limited functionality, G-Has good functionality, E-Has excellent functionality, n/a-Not applicable, has no functionality.

research-oriented applications have underutilized sophisticated statistical analysis methods, which would strengthen the ability to appropriately model the data (i.e., models which incorporate methods to analyze nested multilevel data or spatial statistical analysis methods to take into account geographical proximity). Nor have these studies, for the most part, incorporated positive social indicators to represent community strengths and protective factors.

Analysis of data using spatial and multilevel methods offers several advantages about the structure of the data and proper units of analysis. In the analysis of spatial and multilevel data, software and methods are complex and rapidly evolving. No simple overview can do justice to the broad fields of multilevel and spatial analysis. In the section below, we describe some major decision points, and outline important directions in the analysis of multilevel and spatial data. 
Modeling multilevel data. In a study of community resilience, participants in the same community would be likely to share values of measurements, especially those collected at the community level. For example, all the residents in a particular census tract would share the same value for the poverty rate of that tract. Such shared values would result in a violation of the assumption of independent and identically distributed error terms required by simple analytic techniques such as ordinary least squares regression. One solution is to expand the model to allow for the multilevel nested nature of such data (Hox, 2002). Estimation of multilevel models is conducted so that shared measurement values are accounted for in the construction of the error terms. A more thorough account of the development of multilevel models is provided in Raudenbush and Bryk (2002) and Hox (2002).

Spatial statistical methods. While multilevel models account for the fact that observations within the same social unit will have correlated error terms, they may not always be appropriate techniques for several reasons. First, the definition of spatial units required by multilevel techniques may be somewhat arbitrary or subjective. For example, census tracts may not reflect actual social groupings as perceived by the residents of a community (Sampson et al., 2002). An alternative partitioning of a community into different subareas could conceivably yield different results in a multilevel model. Additionally, multilevel techniques do not account for the contiguity of spatial areas. Spatial analytic techniques do incorporate geographical contiguity of different cases in the analysis. Spatial statistical analyses can be categorized as exploratory (e.g., parallel and coordinate plots, 3D scatterplots, conditional plots, spatial autocorrelation, spatial clustering) or inferential (e.g., OLS and maximum likelihood estimation spatial regression and Empirical Bayes Moran smoothing techniques). For example, clustering methods have been used in epidemiology to model the spread of disease, however are just beginning to be used in the social sciences (Selvin, 1996).

Currently, the evolution of technical capabilities in spatial statistical and spatial analytic methods in the social sciences has enabled the testing of spatially oriented theories. This evolution has been furthered by software applications beyond simple computerized mapping, enabling spatial computations with large geo-linked databases. The acknowledgement of space as a critical variable in analyses is increasing, as is the incorporation of spatial theory in social science. The increasing use of these technologies promotes a convergence of new data and methods, "providing the necessary and sufficient conditions for both conceptual growth and more powerful practical applications" (Goodchild \& Janelle, 2004, p. 444).

\section{CONCLUSIONS}

Along with many other community practitioners, we believe that neighborhoods can have significant effects on the outcomes of children and families. Thus, this commentary has focused on ways to enhance our ability to accurately assess and analyze neighborhood effects. We started by presenting a model that specifically focuses on risk and protective factors at the community/neighborhood level. The model's emphasis on strengths of communities is not revolutionary, as other researchers have also incorporated factors like institutional resources or collective efficacy in their models (e.g., Sampson et al., 2002). However, we feel that a specific focus on strengths is an improvement because it emphasizes the existence of "resilient" communities. As with the resilient children literature, such a focus provides more positives to build from in 
establishing that, despite risk factors such as poverty, crime, and unemployment, there are communities in which children and families reveal more positive outcomes.

One of the major problems in studying neighborhood-level effects is selection bias; that is, the observed "effects" of neighborhoods on individual-level outcomes may be confounded by the presence of unmeasured variables which are correlated with individuals' decisions to live in particular neighborhoods (Sampson et al., 2002). In an important article examining the size of neighborhood effects on a number of youth outcomes, Ginther et al. (2000) found that the size of neighborhood effects was substantially reduced as the characteristics of families and youth were more fully specified in their statistical models. Collecting family-level data in a study of neighborhood effects is an obvious solution, but not necessarily practical. To include such variables requires surveying households-costly in terms of time and resources. In addition, the literature is not exactly clear as to what family/individual characteristics do predict choice of neighborhoods, or, in fact, the extent to which choice is involved in where families live. There is a longstanding concern with selection bias in the social sciences (e.g. Berk, 1983), and several models have been developed to address its presence (Winship \& Mare, 1992). However, to date, relatively few studies have employed these models to address the existence of selection bias when examining neighborhood effects (for an example of such a study see Grogan-Kaylor, 2005). Ideally, with more sophisticated research being conducted on neighborhoods, these models can be adapted and improved.

A challenging conceptual issue is that of indicators versus outcomes; that is, in some analyses, a variable may be a predictor (like crime rates predicting youth outcomes in school), while in other analyses, that same indicator may be the outcome being predicted (for example, unemployment rates or infrastructure maintenance, predicting crime rates). As in any social science research, the choice of predictors and of outcome indicators depends on the theory being tested and/or the social problem being studied.

Another quandary is the operationalization of geographical areas. What constitutes a "neighborhood" is usually determined historically, politically, or administratively (e.g., by government entities). Thus, neighborhoods and communities may have a strong influence on their residents, but not necessarily as captured in our data. Similarly, because a resource is located in a particular community, it is not necessarily a resource to that community. While other resources may be placed in certain communities only because of the availability of a suitable or affordable facility while actively serving residents not in the anticipated proximity.

Another concern noted by Sampson et al. (2002) is that a great deal of research on neighborhood effects has matched a single geocoded address with a census tract to determine the neighborhood in which study participants reside. However, as these authors correctly observe, it is quite possible that an individual might live in one neighborhood, work in second, send their children to school in a third neighborhood, and have friends in many different neighborhoods. Many individuals conduct their activities and access resources based on complex geographic ties. Future research on neighborhood and community effects should try to account for the fact that individuals' lives are lived in multiple geographic settings.

Finally, the dynamic nature of relationships and neighborhoods over time would ideally be taken into account in testing a community resilience model. Neighborhoods change over time, improving with economic development, new housing construction, etc. or worsening due to increased crime, housing abandonment, or lack of infrastructure 
maintenance. Individuals and families also change over time, and neighborhood and family changes can interact. Being able to capture data accurately and completely on point-in-time as well as changes over time for community-level risk and protective factors may be a distant goal, but certainly one worth attaining.

\section{REFERENCES}

Berk, R.A. (1983). An introduction to sample selection bias. American Sociological Review, 40, $386-398$.

Bronfenbrenner, U. (1979). The ecology of human development. Cambridge, MA: Harvard University Press.

Brooks-Gunn, J., Duncan, G.J., \& Aber, J.L. (Eds.). (1997). Neighborhood poverty (Vols. I \& II). New York: Russell Sage Foundation.

Bronfenbrenner, U. (1979). The ecology of human development. Cambridge: Harvard University Press.

Evans, G.W. (2004). The environment of childhood poverty. American Psychologist, 59, 77-92.

Evans, G.W., \& English, K. (2002). The environment of poverty: Multiple stressor exposure, psychophysiological stress, and socioemotional adjustment. Child Development, 73, 1238-1248.

Fraser, M.W., Kirby, L.D., \& Smokowski, P.R. (2004). Risk and resilience in childhood. In M.W. Fraser (Ed.), Risk and resilience in childhood: An ecological perspective (2nd ed., pp. 1366). Washington, DC: NASW Press.

Garbarino, J., \& Sherman, D. (1980). High-risk neighborhoods and high-risk families: The ecology of child maltreatment. Child Development, 51, 188-198.

Garmezy, N. (1993). Children in poverty: Resilience despite risk. Psychiatry, 56, 127-136.

Garmezy, N., Masten, A.S., \& Tellegen, A. (1984). The study of stress and competence in children: A building block for developmental psychopathology. Child Development, 55, 97-111.

Leventhal, T., \& Brooks-Gunn, J. (2000). The neighborhoods they live in: The effects of neighborhood residence on child and adolescent outcomes. Psychological Bulletin, 126, 309-337.

Moos, R.H. (2002). The mystery of human context and coping: An unraveling of clues. American Journal of Community Psychology, 30, 67-88.

O’Donnell, D.A., Schwab-Stone, M.E., \& Muyeed, A.Z. (2002). Multidimensional resilience in urban children exposed to community violence. Child Development, 73, 1265-1282.

Rabe-Hesketh, S., \& Skrondal, A. (2005). Multilevel and longitudinal modeling using stata. College Station: Stata Press.

Raudenbush, S.W., \& Byrk, A.S. (2000). Hierarchical linear models: Applications and data analysis methods. Thousand Oaks: Sage.

Richman, J.M., Bowen, G.L., \& Woolley, M.E. (2004). School failure: An ecological-interactionaldevelopmental perspective. In M.W. Fraser (Ed.), Risk and resilience in childhood: An ecological perspective (2nd ed.). Washington, DC: NASW Press.

Rutter, M. (1987). Psychosocial resilience and protective mechanisms. American Journal of Orthopsychiatry, 57, 316-331.

Sampson, R.J., Morenoff, J.D., \& Gannon-Rowley, T. (2002). Assessing "neighborhood effects": Social processes and new directions in research. Annual Review of Sociology, 28, 443-478.

Seccombe, K. (2002). "Beating the odds" versus "changing the odds": Poverty, resilience and family policy. Journal of Marriage and Family, 64, 384-394.

Wandersman, A., \& Nation, M. (1998). Urban neighborhoods and mental health. American Psychologist, 53, 647-656.

Werner, E.E., \& Smith, R.S. (1982). Vulnerable but invincible: A longitudinal study of resilient children and youth. New York: McGraw-Hill Book Company. 
Wier, K.R., \& Robertson, J.G. (1998). Teaching geographic information systems for social work applications. Journal of Social Work Education, 34, 81-96.

Wilson, W.J. (1987). The truly disadvantaged: The inner city, the underclass, and public policy. Chicago: University of Chicago Press.

Wilson, W.J. (1996). When work disappears: The world of the new urban poor. New York: Knopf.

Winship, C., \& Mare, R.D. (1992). Models for sample selection bias. Annual Review of Sociology, $18,327-50$.

Wong, Y-L.I., \& Hillier, A.E. (2001). Evaluating a community-based homelessness prevention program: A geographic information system approach. Administration in Social Work, 25(4), $21-45$. 